University of Nebraska - Lincoln

DigitalCommons@University of Nebraska - Lincoln

1994

\title{
Effects of lithology and depth on the permeability of core samples from the Kola and KTB drill holes
}

\author{
C. Morrow \\ U.S. Geological Survey \\ D. Lockner \\ U.S. Geological Survey \\ S. Hickman \\ U.S. Geological Survey \\ M. Rusanov \\ Nedra Enterprise \\ T. Röckel \\ Kontinentales Tiefbohrprogramm der Bundesrpublik
}

Follow this and additional works at: https://digitalcommons.unl.edu/usgsstaffpub

Part of the Earth Sciences Commons

Morrow, C.; Lockner, D.; Hickman, S.; Rusanov, M.; and Röckel, T., "Effects of lithology and depth on the permeability of core samples from the Kola and KTB drill holes" (1994). USGS Staff -- Published Research. 408.

https://digitalcommons.unl.edu/usgsstaffpub/408

This Article is brought to you for free and open access by the US Geological Survey at DigitalCommons@University of Nebraska - Lincoln. It has been accepted for inclusion in USGS Staff -- Published Research by an authorized administrator of DigitalCommons@University of Nebraska - Lincoln. 


\title{
Effects of lithology and depth on the permeability of core samples from the Kola and KTB drill holes
}

\author{
C. Morrow, D. Lockner, and S. Hickman \\ U.S. Geological Survey, Menlo Park, California
}

\author{
M. Rusanov \\ Nedra Enterprise, Zapolyarny, Russia
}

\section{T. Röckel}

Kontinentales Tiefbohrprogramm der Bundesrepublik, Windischeschenbach, Germany

\begin{abstract}
Permeability measurements were conducted on intact core samples from the Kola drill hole in Russia and the KTB drill hole in Germany. Samples included granodiorite gneisses, basalts and amphibolites from depths up to $11 \mathrm{~km}$. The tests were intended to determine the pressure sensitivity of permeability and to compare the effects of stress relief and thermal microcracking on the matrix permeability of different rock types and similar samples from different depths. The pore pressure $P_{p}$ was fixed at the estimated in situ pressure assuming a normal hydrostatic gradient; the confining pressure $P_{c}$ was varied to produce effective pressures $\left(P_{e}=P_{c}-P_{p}\right)$ of 5 to $300 \mathrm{MPa}$. The permeability of the basaltic samples was the lowest and most sensitive to pressure, ranging from $10^{-20}$ to $10^{-23} \mathrm{~m}^{2}$ as effective pressure increased from 5 to only $60 \mathrm{MPa}$. In contrast, the granodiorite gneiss samples were more permeable and less sensitive to pressure, with permeability values ranging from $10^{-17}$ to $10^{-22} \mathrm{~m}^{2}$ as effective pressures increased to $300 \mathrm{MPa}$. Amphibolites displayed intermediate behavior. There was an abundance of microfractures in the quartz-rich rocks, but a relative paucity of cracks in the mafic rocks, suggesting that the observed differences in permeability are based on rock type and depth, and that stress relief/thermal-cracking damage is correlated with quartz content. By applying the equivalent channel model of Walsh and Brace [1984] to the permeability data of the quartz-rich samples, we can estimate the closure pressure of the stress-relief cracks and thereby place bounds on the in situ effective pressure. This method may be useful for drill holes where the fluid pressure is not well constrained, such as at the Kola well. However, the use of crack closure to estimate in situ pressure was not appropriate for the basalt and amphibolite samples, because they are relatively crack-free in situ and remain so even after core retrieval. As a result, their permeability is near or below the measurable lower limit of our apparatus at the estimated in situ pressures of the rocks.
\end{abstract}

\section{Introduction}

At $12.3 \mathrm{~km}$, the Kola well in Russia is the world's deepest. It penetrates a variety of formations, including Proterozoic basic rocks, Archean schists and Archean gneisses [Kozlovsky, 1987; Kremenetsky, 1991] and provides the opportunity to study the physical properties of diverse rocks from depths hitherto unattainable. In addition, the KTB well in Germany, drilled to a depth of $7 \mathrm{~km}$ through predominantly mafic rocks [Emmer-

Copyright 1994 by the American Geophysical Union.

Paper number 93JB03458.

0148-0227/94/93JB-03458\$05 00 mann et al., 1992], enables us to compare the properties of similar rock types from two different drill holes. In this paper, we investigate the matrix permeability and electrical resistivity of selected cores from these two sites under elevated confining and fluid pressures in order to understand better such processes as fluid migration in the midcrust, generation and maintenance of excess fluid pressure, convective heat flow, metamorphic processes, and deformation and faulting mechanics. The use of deep core samples is advantageous for three reasons. First, outcropping (surface) specimens of equivalent mineralogy may be altered in unknown ways due to unloading and near-surface weathering. Second, in situ measurements of permeability and fluid pressure may not be possible in some wells, such as at Kola. Third, measurements on core samples provide the only 
direct means of assessing matrix permeability, as in situ permeability tests in low-porosity crystalline rocks are likely to be dominated by flow through macroscopic fractures [e.g., Brace, 1980].

Previous studies on the permeability of Kola core samples have produced a variety of results. Bayuk et al. [1987], reported that core permeabilities were $10^{-15}$ to $10^{-17} \mathrm{~m}^{2}\left(1 \mathrm{~m}^{2}=10^{12}\right.$ Darcy) and that permeability and porosity increased with depth, while density decreased with depth. They attributed the permeability behavior to changes in rock composition and to secondary processes, such as nonuniform tectonic stresses, which might have caused microfracturing, increases in porosity, and elevated permeabilities at depth. However, these tests were made at effective pressures of less than $100 \mathrm{MPa}$, well below the estimated in situ pressure. Lockner et al. [1991] reported that the permeability of three cores of differing mineralogy from near the bottom of the drill hole at effective pressures to $400 \mathrm{MPa}$ were $10^{-17}$ to $10^{-22} \mathrm{~m}^{2}$, at least 2 orders of magnitude lower than the results of Bayuk et al., [1987]. The latter experiments showed strong pressure sensitivity of permeability, possibly caused by the closure of microfractures produced by stress relief and cooling during coring and sample retrieval. This different interpretation of the origin of microfractures emphasizes the importance of measuring permeability under in situ pressure conditions.

In this paper we expand on the work of Lockner et al. [1991] by investigating the pressure sensitivity of permeability and electrical resistivity of several different samples from the Kola and KTB drill holes and how permeability scales with depth in mineralogically similar rocks. The measurements presented here provide a lower bound on the permeability of the rock mass expected at depth, since the cores do not sample the highly fractured or mineralized fissure zones described by Kazansky et al. [1987] for the Kola well and $E m$ mermann et al. [1992] for the KTB well. In addition to direct measurements of matrix permeability and resistivity, we must also address the unavoidable effect of stress relief and thermal cracking on the physical properties of the rocks. Such fractures occur on many scales, from grain-scale fractures due to the mismatch in elastic moduli and due to thermal stresses between grains upon unloading, to the larger-scale subhorizontal disking fractures caused by the action of the drill bit [see Engelder, 1993]. We expect both types of fractures to become more numerous with increasing depth, as is observed in other drill holes. For this analysis we use the equivalent channel model of Walsh and Brace [1984] to determine the geometric and elastic properties of the stress relief versus natural fractures in the cores. By estimating the pressure at which the stress relief fractures close, we can, in the absence of downhole fluid-pressure measurements, place bounds on the in situ effective pressure.

\section{Experimental Procedure}

Permeability experiments were conducted on intact cylinders of granodiorite, basalt, and amphibolite (see
Tables 1 and 2), $2.54 \mathrm{~cm}$ in diameter. Lengths varied according to material availability but were generally $1.27 \mathrm{~cm}$ for the Kola samples and $2.54 \mathrm{~cm}$ for the KTB samples. The samples were machined from the most homogeneous sections available, and veined regions were avoided. However, gneissic textures were present on many scales in both drill holes. The Kola samples were chosen from cores ranging to the bottom of the drill hole. In addition, surface equivalents of granodiorite and amphibolite were collected from nearby outcrops. In the KTB suite, three mutually perpendicular samples, one vertical and two horizontal, were cut from the oriented core recovered from the 1252 and $3607 \mathrm{~m}$ depth levels. These samples were aligned along the three principal stress directions: $S_{v}$, the vertical stress; $S_{h}$, the least horizontal stress; and $S_{H}$, the greatest horizontal stress (see Table 2). Thus we could test for permeability anisotropy in these rocks.

For each sample, pore pressure for the experiment was fixed at the in situ pressure estimated by assuming a normal hydrostatic gradient. The in situ confining pressure was assumed to equal $S_{v}$ and was calculated from average density measurements: $2.84 \mathrm{Mgm} / \mathrm{m}^{3}$ for the granodiorites and $2.95 \mathrm{Mgm} / \mathrm{m}^{3}$ for the mafic samples from Kola, and $2.97 \mathrm{Mgm} / \mathrm{m}^{3}$ for the KTB samples. Effective pressures $\left(P_{e}=P_{c}-P_{p}\right)$ from 5 to $300 \mathrm{MPa}$ (Kola) and 5 to $60 \mathrm{MPa}$ (KTB) were achieved by increasing confining pressure while holding the pore pressure at the estimated in situ value. Care was taken to avoid hysteresis during the initial loading by increasing pore pressure and confining pressure in a stepwise fashion, so as not to exceed the first effective pressure value of the series. After each pressure increase, and before the start of the permeability measurement, the volume of fluid expelled from the sample was measured. This equilibration period lasted from tens of minutes to over a day, depending on the porosity and permeability of the sample and the applied pressure. Thus the samples were held at pressure for different lengths of time before the start of the measurements.

Permeability was measured at room temperature using a steady-state flow technique [Morrow and Byerlee, 1992], in which fluid pressure at the sample inlet was maintained 1 to $2 \mathrm{MPa}$ above that at the outlet. Mea-

Table 1. Kola Samples

\begin{tabular}{lcccc}
\hline Description & Depth, m & $P_{e}, \mathrm{MPa}^{*}$ & Porosity $\phi$ & $r^{\dagger}$ \\
\hline Gneiss & surface & $\ldots$ & 0.0030 & 2.184 \\
Diabase & surface & $\ldots$ & 0.0072 & + \\
Diabase & 936 & 17.9 & 0.0081 & + \\
Metadiabase & 2948 & 56.3 & 0.0037 & 2.671 \\
Amphibolite & 6320 & 120.0 & 0.0031 & + \\
Gneiss & 7042 & 127.0 & 0.0087 & 2.266 \\
Amphibolite & 8723 & 166.9 & 0.0069 & + \\
Gneiss & 11658 & 210.0 & 0.0058 & 2.005 \\
\hline
\end{tabular}

* Estimated in situ effective pressure based on depth and rock density.

${ }^{\dagger}$ From equation 5 .

${ }^{+}$Not measured, $r$ for $2948 \mathrm{~m}$ rock was used for other mafic samples. 
Table 2. KTB Amphibolite Samples

\begin{tabular}{ccccc}
\hline $\begin{array}{c}\text { Depth, } \\
\mathrm{m}\end{array}$ & $\begin{array}{c}\text { Core } \\
\text { Orientation }\end{array}$ & $\begin{array}{c}\text { Principal } \\
\text { Stress }\end{array}$ & $\begin{array}{c}\text { Stress Magnitude } \\
\mathrm{MPa}^{*}\end{array}$ & $\begin{array}{c}\text { Porosity } \\
\phi^{\dagger}\end{array}$ \\
\hline 1252.6 & vertical & $S_{v}$ & 35.0 & 0.0075 \\
1252.6 & $\mathrm{~N} 65^{\circ} \mathrm{E}$ & $S_{h}$ & 29.1 & $"$ \\
1252.6 & $\mathrm{~N} 155^{\circ} \mathrm{E}$ & $S_{H}$ & 57.4 & $"$ \\
3607.9 & vertical & $S_{v}$ & 101.0 & 0.0056 \\
3607.9 & $\mathrm{~N} 85^{\circ} \mathrm{E}$ & $S_{h}$ & 55.7 & $"$ \\
3607.9 & $\mathrm{~N} 175^{\circ} \mathrm{E}$ & $S_{H}$ & 111.4 & $"$ \\
\hline
\end{tabular}

* Estimated in situ principal stresses at depth based on in situ stress gradient measurements. For effective pressure values, subtract $12.3 \mathrm{MPa}\left(P_{p}\right.$ at $\left.1252 \mathrm{~m}\right)$ or $35.4 \mathrm{MPa}\left(P_{p}\right.$ at $3607 \mathrm{~m}$ ).

${ }^{\dagger}$ Average porosity of the three samples at each depth.

surements extended over 24 to 48 hours to assure equilibrium. Permeability $k$ was calculated using Darcy's law:

$$
q / A=(k / \mu)(d P / d x)
$$

where $q$ is the measured flow rate, $A$ is the crosssectional area of the sample, $m$ is the dynamic viscosity of water $(1.0 \mathrm{cP}$ in these experiments) and $(d P / d x)$ is the fluid pressure gradient over the length of the sample. Temperature in the experimental chamber was maintained at $27 \pm 0.02^{\circ} \mathrm{C}$ to assure accurate fluid volume measurements. With this careful temperature control and the small volume of the pore pressure intensifier on the inlet side of the sample $(0.250 \mathrm{cc})$, permeability could be measured to values as low as $10^{-23} \mathrm{~m}^{2}$. Accuracy of the measurements varied with permeability and was approximately $\pm 5 \%$ for values above $10^{-20} \mathrm{~m}^{2}$; $\pm 10 \%$ between $10^{-20}$ and $10^{-22} \mathrm{~m}^{2}$; and around $\pm 20 \%$ below $10^{-22} \mathrm{~m}^{2}$. These uncertainties do not reflect effects of time-dependent behavior between measurements or stress cycling, which are discussed in the following section. In addition to the flow tests, electrical resistivity was measured on the same granodiorite Kola samples and 2948-m basaltic Kola sample used in the permeability tests, using a $100-\mathrm{Hz}$ sine wave $(1 \mathrm{~V}$ peakto-peak amplitude) and a $0.1 \mathrm{M} \mathrm{KCl}$ solution for the pore fluid. Effective pressures for these experiments matched those of the permeability measurements.

\section{Permeability}

Selected Kola samples were cycled under pressure to test for repeatability and hysteresis effects. A typical permeability result is shown in Figure 1 for the 7042$\mathrm{m}$ granodiorite, with two loading cycles. Permeability decreased from around $10^{-18}$ to $10^{-22} \mathrm{~m}^{2}$ at pressures to $250 \mathrm{MPa}$. Values during loading were higher than during unloading due to time-dependent relaxation processes, as is characteristic of many rocks and granular materials. In addition, permeabilities during the second loading cycle (conducted immediately after the first) were slightly lower than those during the first for the same reasons. In tests on Westerly Granite, permeability may recover almost completely if a time interval is allowed between cycles [Morrow et al, , 1986]. The

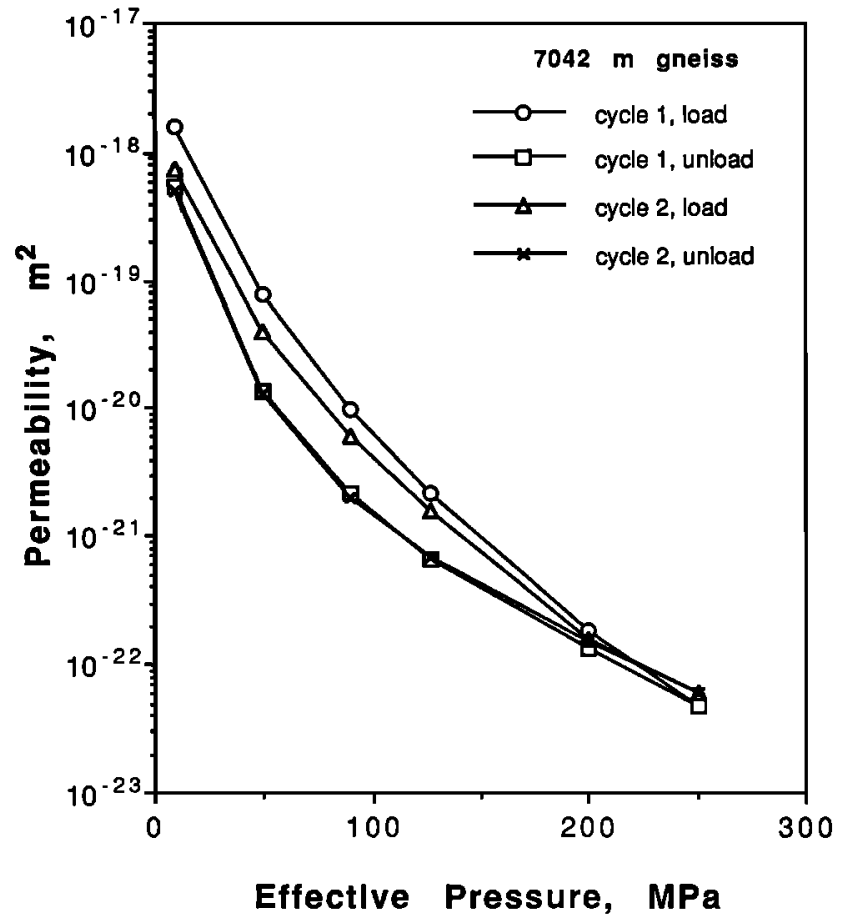

Figure 1. Permeability of Kola granodiorite gneiss from $7042 \mathrm{~m}$ depth, with two cycles of loading and unloading. Permeability measurement errors are generally smaller than the symbol size in this and subsequent plots.

7042-m sample shows fairly consistent permeability values between cycles, particularly during unloading, even without allowing for time-dependent relaxation. In contrast, the deepest granodiorite sample $(11,685 \mathrm{~m})$, was extremely friable, presumably due to excessive stress relief damage upon core retrieval, and measurements on that sample were not repeatable. The sample became increasingly less permeable with cycling (Figure 2, loading curves only), indicating that permanent damage accumulated during testing. For the four cycles shown, permeability decreased by about an order of magnitude at a given pressure. This difference in the elastic response of midhole and deep samples illustrates that some cores from extreme depths may have limited use for laboratory testing of physical properties. Because repeated cycling damages the samples, particularly if 


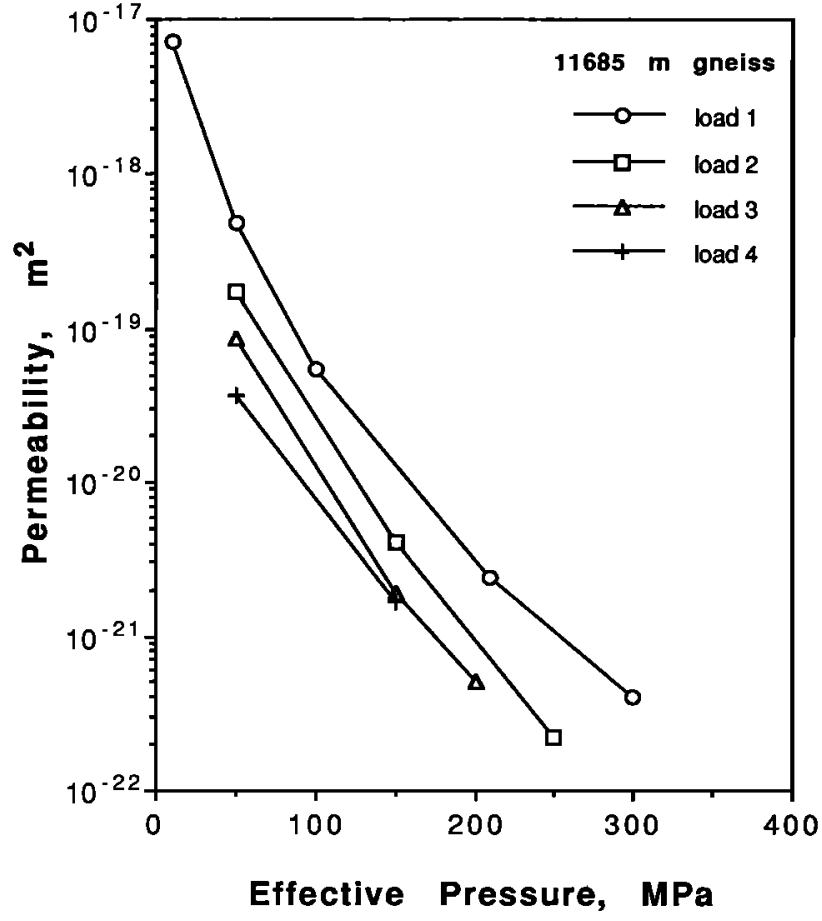

Figure 2. Permeability of Kola gneiss from $11,685 \mathrm{~m}$, with four loading cycles. Permanent damage to this friable sample caused permeability to decrease with each loading cycle.

stress relief effects are already significant, only the first loading curve of each is described below.

The permeabilities of the Kola samples, plotted as a function of effective pressure in Figure 3, cover 6 orders of magnitude $\left(10^{-17}\right.$ to $\left.10^{-23} \mathrm{~m}^{2}\right)$. In many cases the pressure range of the experiments was dictated by the lower permeability limit of the experimental system $\left(10^{-23} \mathrm{~m}^{2}\right)$. The granodiorite gneisses were generally more permeable than the mafic samples. We attribute these differences in permeability to variations in texture, mineralogy, and sample depth. First, the mafic rocks were much finer grained than the quartzrich rocks. If grain boundary cracks predominate, then flow around grain boundaries of the mafic samples must follow a more tortuous path, leading to lower permeabilities [Bear, 1972]. Mineral assemblage is also important because quartz grains in the granodiorites were more often fractured than the mafic minerals. Finally, depth is a factor because (with the exception of the surface sample) the granodiorites were from deeper sections of the drill hole and thus may have sustained more stress relief and thermal cracking upon retrieval to the surface. Alternatively, they may have been subjected to nonuniform tectonic stresses.

Note that in general, the initial permeabilities as well as the permeabilities at elevated effective pressure increase with increasing sample depth, suggesting that stress relief and thermal fracturing dominated much of the permeability at low effective pressures. Values at the estimated in situ pressures, assuming a normal hydrostatic gradient, are shown as open symbols on each curve (surface samples excluded). These values range between $5 \times 10^{-21}$ and $5 \times 10^{-23} \mathrm{~m}^{2}$, which is exceptionally low compared to other rocks [e.g., Brace, 1980]. If fluid pressures are above hydrostatic in certain parts of the well, as suggested by Borevsky et al. [1987], then in situ permeabilities would be higher than those reported here.

The pressure sensitivity of permeability (as determined by the slope of the curves in Figure 3 ) is proportional to depth as well as pressure. It should be noted that sensitivity to pressure combines the effects of many different factors. For example, like most rocks, the permeability of the Kola samples decreased more rapidly at low pressures than at higher pressures, indicating that cracks are more difficult to close (they become stiffer) as pressure is raised. However, the Kola samples are much more pressure sensitive than most rocks obtained from surface outcrops. The permeability of Westerly, Barre or other granites does not decrease to $10^{-21} \mathrm{~m}^{2}$ until pressures of several hundred megapascals are applied (Figure 3) [Brace et al., 1968]. The Kola permeabilities, in contrast, drop rapidly to low values with a modest increase in pressure much the same as the core samples from the Cajon Pass well in California [Morrow and Byerlee, 1992]. At Cajon Pass, extremely low permeabilities were observed for a variety of crystalline rocks at relatively low pressures $\left(P_{e}<60 \mathrm{MPa}\right)$, suggesting that there are differences in permeability behavior between samples that have been near the surface for a long time and those retrieved from deep drill holes. Such differences are not fully understood but are probably related to the long-term effects of weathering and near-surface

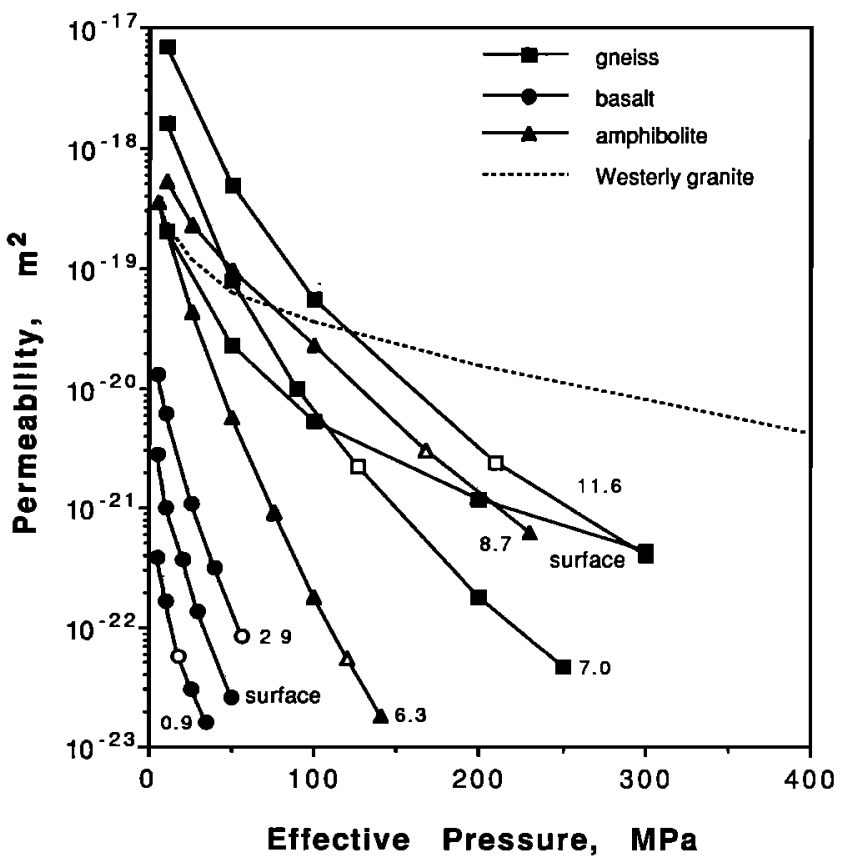

Figure 3. Permeability of Kola core samples (loading only), with surface or depth in kilometers indicated. Pore pressure for each sample was fixed at the estimated in situ value. Measurements at the estimated in situ effective pressures are shown as open symbols. Westerly granite [Brace et al., 1968] included for comparison. 
crack sealing and mineralization on cracks and pores. In a later section, we further investigate the pressure sensitivity of permeability using the Walsh and Brace [1984] model.

The permeabilities of the KTB samples (Figure 4) were sufficiently low that measurements could not be made at pressures above $60 \mathrm{MPa}$ for many of the samples. As a result, measurements at in situ effective pressures could be made for the 1252-m sample $\left(S_{v}=\right.$ $22.7 \mathrm{MPa}$ at $1252 \mathrm{~m}$ ) but not for the $3607-\mathrm{m}$ sample $\left(S_{v}=65.6 \mathrm{MPa}\right.$ at $\left.3607 \mathrm{~m}\right)$. Test pressures also included $S_{H}$ for the 1252 sample and $S_{h}$ for the 3607 sample (see Table 2). These experiments were conducted with isotropic loading, as we cannot vary all three principal stresses independently in our apparatus.

The permeabilities of the KTB rocks (Figure 4) cover more than 4 orders of magnitude $\left(10^{-19}\right.$ to $\left.10^{-23} \mathrm{~m}^{2}\right)$ and show an extreme pressure sensitivity. These data divide into two distinct groups separated by 2 orders of magnitude. The groupings do not depend on depth, illustrating the effect of sample anisotropy on permeability and the importance of measuring the complete permeability tensor, even for samples that appear uniform in hand specimen.

It is interesting to note that the permeability for many of these samples follows the simple relation $-\log k$ $\propto P_{e}(1252 \mathrm{~m}$, in particular). Such systematics are not normally observed and none of the Kola samples, even

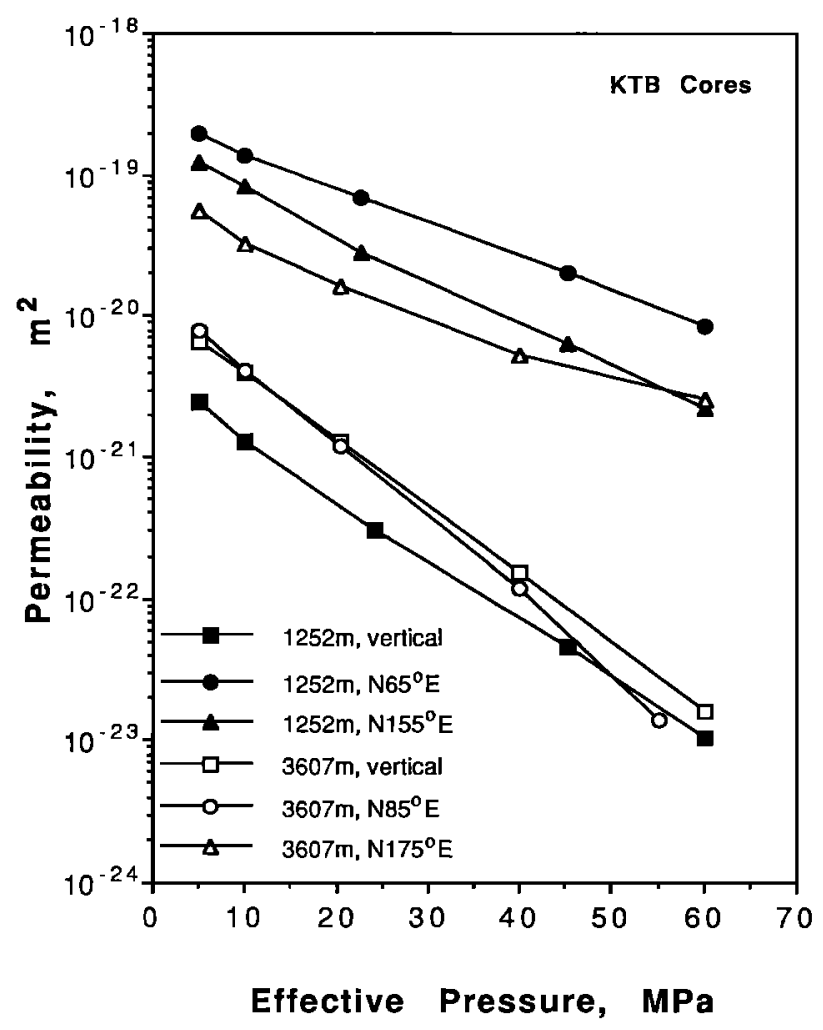

Figure 4. Permeability of KTB core samples from depths of 1252 and $3607 \mathrm{~m}$. At each depth, three mutually perpendicular vertical and horizontal cores were oriented along the principal stress directions $S_{v}$ (verti$\mathrm{cal}), S_{h}\left(\mathrm{~N} 65^{\circ} \mathrm{E}, \mathrm{N} 85^{\circ} \mathrm{E}\right)$, and $S_{H}\left(\mathrm{~N} 155^{\circ} \mathrm{E}, \mathrm{N} 175^{\circ} \mathrm{E}\right)$. the mafic cores, can be described so simply. These KTB results imply that pressure sensitivity of permeability is nearly exponential, at least at effective pressures below $60 \mathrm{MPa}$. Therefore permeability reduction in these rocks is probably not controlled entirely by the closure of high-aspect-ratio cracks. Whether the trend will continue to higher pressures is not known.

\section{Direct Observation of Microcracks}

The permeability values in Figure 3 suggest that microcrack density increases with sample depth. However, are these cracks present in situ or are they artifacts of drilling and core retrieval? Additionally, is there some depth above which decompression damage is less likely to occur due to the elastic strength of the rock? Kremenetsky [1990] observed a pronounced increase in porosity below $4.5 \mathrm{~km}$ in the Kola well and interpreted this increase to be the result of hydrofracturing at depth caused by metamorphic dehydration. Bayuk et al. [1987] also rely on in situ microfractures to explain their high-permeability values at depth. Pavlenkova [1988], on the other hand, showed that downhole resistivity, seismic velocity, and other physical parameters were relatively unaffected throughout the depth of the drill hole, indicating that microfractures, which strongly influence those properties, were probably not present in situ. Laboratory studies of seismic velocity (L.Vernik, personal communication, 1993), made on the same Kola core samples that we have studied, also suggest that most of the observed microcracks resulted from drilling-induced damage. Studies on other drill holes tend to support this latter view. Wang and Simmons [1978] and Carlson and Wang [1986] suggest that some rocks may be virtually crack-free in situ, based on seismic velocity correlations, anelastic strain recovery and microstructural observations.

Petrographic observations of microfractures in our Kola samples corroborate the observations of higher permeability and increased stress relief microfracturing at greater depths (KTB samples are considered separately below). Some of the fractures have characteristics clearly suggesting that they formed naturally. For example, Figure 5, (7042-m gneiss) shows typical fractures and pores present in the quartz grains of all the gneissic cores from Kola regardless of depth. Some cracks are open and unhealed, whereas extensive crack healing has nearly or completely closed others. The irregular strings of bubbles visible in the photomicrograph along old crack traces are characteristic of crack healing [e.g., Smith and Evans, 1984; Brantley et al., 1990]. Such features were also common in core samples from the Cajon Pass drill hole in Southern California [Morrow and Byerlee, 1992]. Brantley et al. [1990] note that microcracks (such as those visible in Figure 5) can serve as conduits for fluid flow as long as the bubbles and tubes remain interconnected but that crack lifetimes are geologically short, especially at elevated temperatures as shown by Moore et al. [1993]. 


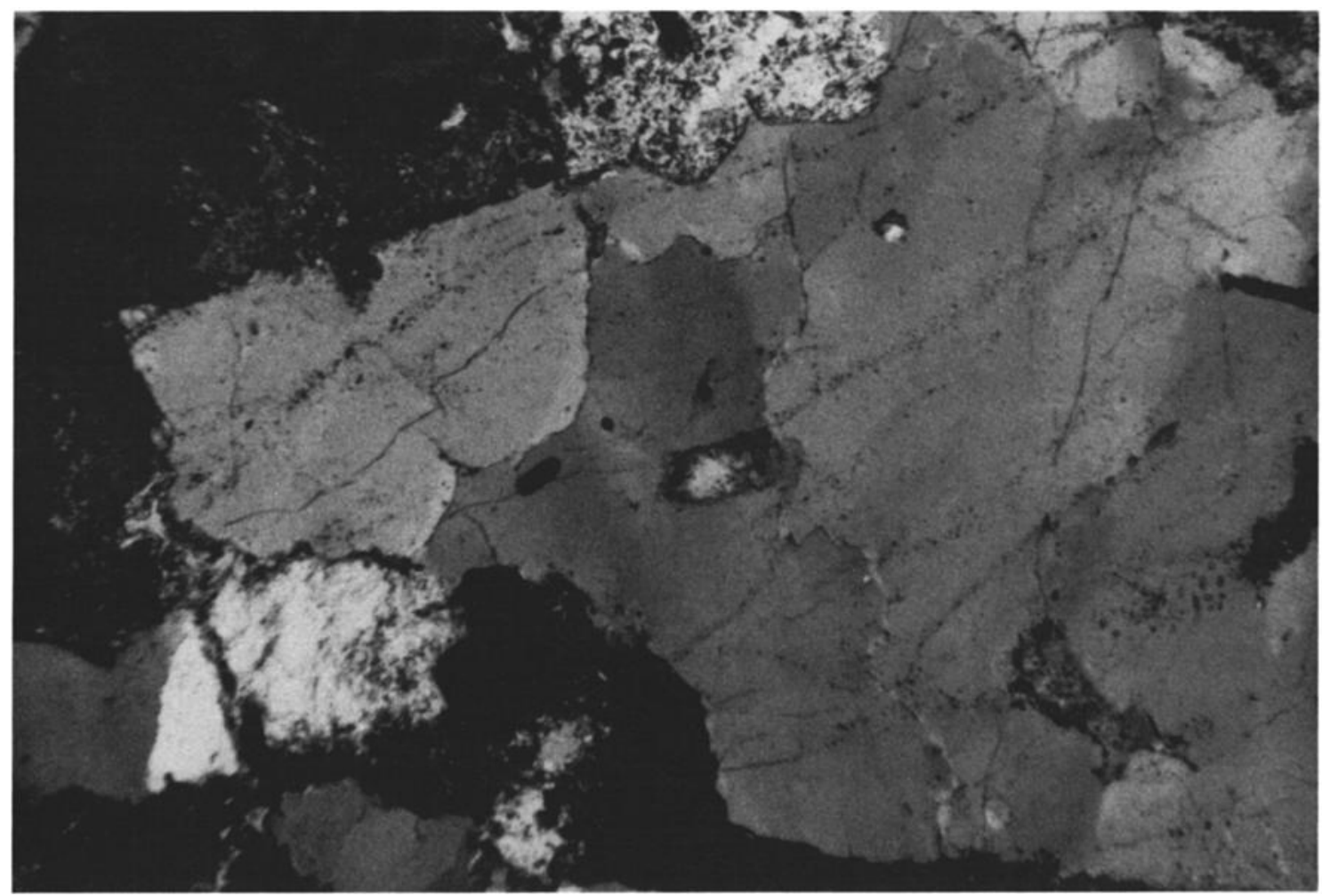

Figure 5. Photomicrograph of the $7042 \mathrm{~m}$ gneissic Kola sample showing partially healed fractures, which appear as strings of bubbles in the quartz grains. Image is $3.6 \mathrm{~mm}$ across.

Other areas of the sample show clear evidence of secondary mineralization, where cracks have been sealed partially or completely with calcite, chlorite, phyllosilicates or other minerals. Partially sealed cracks can also be natural conduits for fluid flow, although they too may be short-lived. Cross-cutting relationships among these secondary features reveal numerous episodes of hydrothermal fracturing and alteration, processes which can cyclically increase and decrease permeability, as discussed by Sibson [1981].

Stress relief fractures are very different in character and scale. Figure 6 shows a small disking fracture from the $11,685-\mathrm{m}$ gneissic sample near the bottom of the Kola drill hole, which is oriented normal to the core axis. The mechanism of formation of these disking fractures and their potential utility as in situ stress indicators are discussed by Dyke [1989] and Kulander et al. [1990]. This fracture is fresh (i.e., contains no secondary minerals), well matched, and rougher (i.e., exhibits larger asperities) than the features in Figure 5. Cracks of this size were not observed in the shallower samples, a fact consistent with the assumption that stress relief damage increases with depth [e.g., Kowallis and Wang, 1983; Wang and Simmons, 1978]. In addition, numerous biotite grains in this sample exhibit fresh cleavage, suggesting decompression damage.

The mafic samples from both drill holes do not contain any obviously fresh fractures as seen in the quartzrich samples. This fact, together with the lower permeabilities of the mafic samples, implies that they were retrieved relatively damage-free. We will show that this is probably true for samples shallower than about $3 \mathrm{~km}$. We emphasize that stress relief fracturing occurs on many scales; the particularly obvious feature in Figure 6 was chosen for illustration. Smaller microfractures caused by thermal cracking, elastic modulus mismatch and other stress relief processes may be difficult or impossible to see in standard thin sections and may require reflected light observations or the use of a scanning electron microscope for identification.

Many studies link orientations of stress relief microfractures with borehole breakouts, hydraulic fractures and shear wave birefringence to determine in situ stress directions [e.g., Wang and Sun, 1990; Carlson and Wang, 1986]. This was not possible with the Kola samples because the cores were not oriented. However, the KTB samples were cored along previously determined principal stress directions (Table 2), providing us with an opportunity to relate permeability to stress directions. Petrographic observation of cores from $1252 \mathrm{~m}$ revealed that thin, short fractures which often followed hornblende cleavage directions tended to be horizontal, consistent with the observation of high horizontal permeability and low vertical permeability. Larger, through-going fractures were completely filled with calcite and generally occurred at $45^{\circ}$ to $S_{h}$ and $S_{H}$, as might be expected from shear features, although shear offset could not be easily detected in thin section. In this sample, the direction of greatest permeability was aligned with $S_{h}$. The samples at $3607 \mathrm{~m}$ differed, having the high permeability along $S_{H}$. Partially filled veins may have been responsible for this difference in perme- 


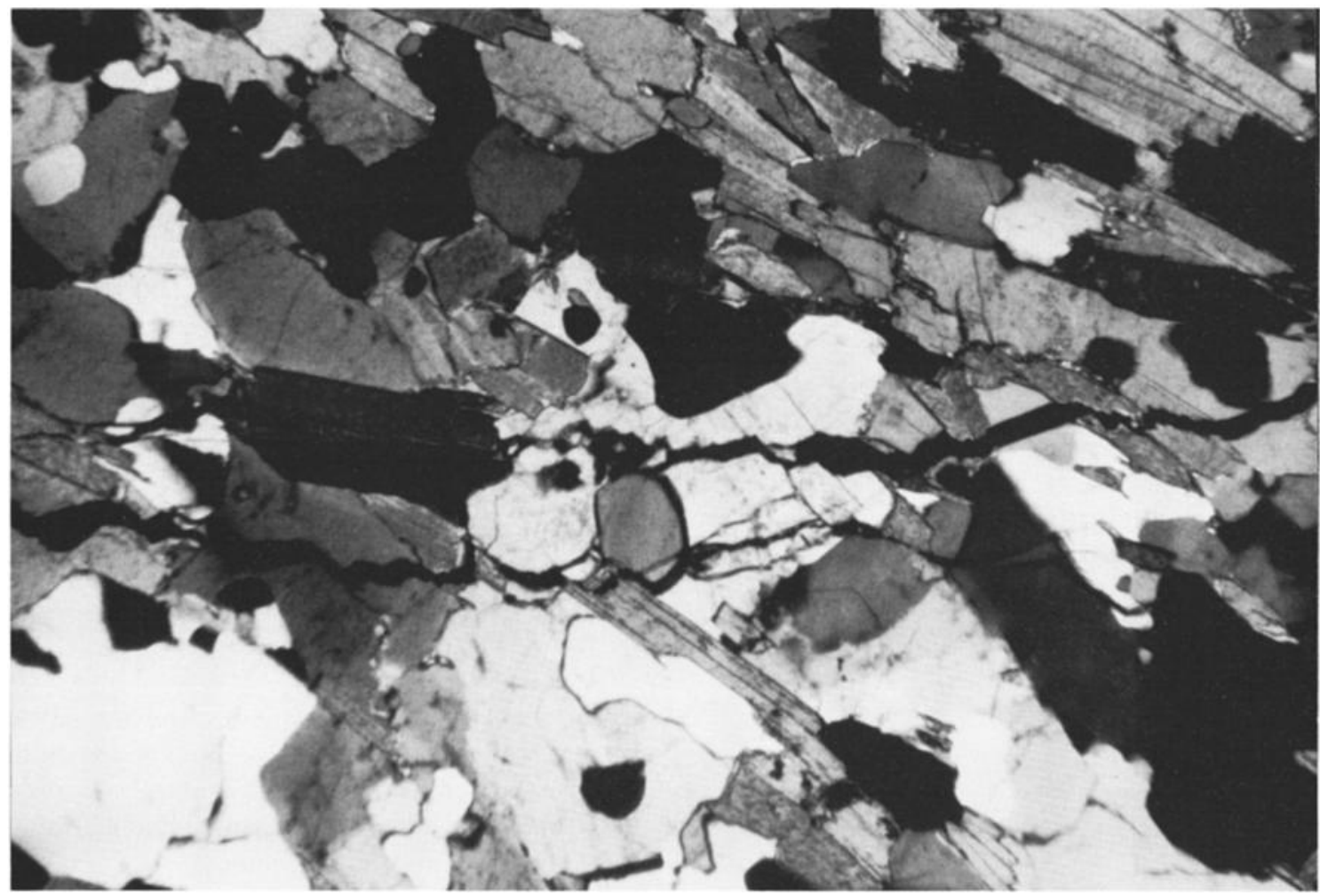

Figure 6. Disking fracture in the $11,685 \mathrm{~m}$ gneissic Kola sample is clean, well mated and larger than typical natural features. Image is $3.6 \mathrm{~mm}$ across.

ability anisotropy since they were abundant in planes normal to the $S_{H}$ direction.

These petrographic results shows that both natural and drilling-induced fractures have diverse characteristics that influence sample permeability and permeability anisotropy. On the basis of our measurements and observations at KTB, we speculate that the gneissic samples from Kola might have also displayed significant permeability anisotropy. Unfortunately, multidirectional cores are not available from the Kola drillhole. The observations suggest that as a result of stress relief and thermal cracking, the permeability of cores from deep drillholes should not be taken at face value, but must be measured at the appropriate in situ pressure. How, for instance, can we estimate the permeability at depth from measurements on shallow basalt cores? The results presented in Figure 3 suggest permeability differences of several orders of magnitude at comparable pressures for samples from different depths that are mineralogically and physically very similar.

\section{Equivalent Channel Model}

From the comparison of the natural fractures in Figure 5 and the drilling-induced fractures in Figure 6 , we make the important assumption that the geometric properties (surface relief, asperity height, roughness etc.) of natural fractures must differ from those of stress relief fractures. Because crack behavior is strongly dependent on applied pressure, we expect the two types of cracks to respond differently as pressure is increased (i.e., one should be more or less compliant than the other). To further investigate this hypothesis, we follow the "equivalent channel model" of Walsh and Brace [1984] on the relation between permeability and electrical resistivity. They assume that the flow paths for hydraulic and electrical conductivity are the same. Although this assumption is difficult to prove, David [1993] shows in numerical models that the flow paths should differ only for pore geometries that approach the percolation threshold, which is not the case in these experiments. With the limitations of this important assumption in mind, there are many relationships that follow from the equivalent channel analysis, and we make note of the most relevant of these to our current work. The crack aperture $a$ of the idealized equivalent channel is related to permeability $k$ and formation factor $F$ by the expression

$$
\Delta a=\Delta(3 k F)^{1 / 2}
$$

where $F$ is the ratio of the resistivity of the rock to the resistivity of the electrolyte. Assuming that the cracks contain asperities with an exponential distribution of heights [Greenwood and Williamson, 1966], the change in crack aperture resulting from a change in pressure is

$$
d a=\sqrt{2} h(d p / p)
$$

where $h$ is the rms asperity height. Relating equations (2) and (3) gives

$$
d(3 k F)^{1 / 2}=\sqrt{2} h(d p / p) .
$$


Thus a plot of aperture versus $\ln$ p should result in a straight line with slope proportional to $h$. Walsh and Brace [1984] verified that this relation held for a number of samples taken from surface outcrops. However, our petrographic observations of the core samples suggest that stress relief and thermally produced cracks may have a different distribution of asperity heights than in situ cracks. In this paper we do not attempt to describe the statistical distribution of asperity heights that correspond to such fractures, as no quantitative analysis has been made. However, we expect to find a change in slope of aperture versus $\ln p$ at the pressure where stress relief cracks are closed and in situ cracks dominate the flow path.

To illustrate the applicability of the equivalent channel model to our core samples, in Figure 7 we show a typical data set of electrical response relative to permeability for the 11,685-m gneissic Kola sample. These data follow the relation

$$
k=c F^{-r}
$$

where $c$ is a constant and the slope $r$ is a measure of the sensitivity of tortuosity to changes in crack aperture, with theoretical limits $1 \leq r \leq 3$ [Walsh and Brace, 1984]. Tabulations of $r$ for the other Kola core samples are given in Table 1. From the straight line shown in Figure 7 and using the Walsh and Brace model, we infer that the sample behaves elastically and that the flow paths for permeability and resistivity can be considered the same. By combining (2) with (5), we find that aperture is proportional to $k^{n}$, where $n=(r-1) / 2 r$, and finally, that

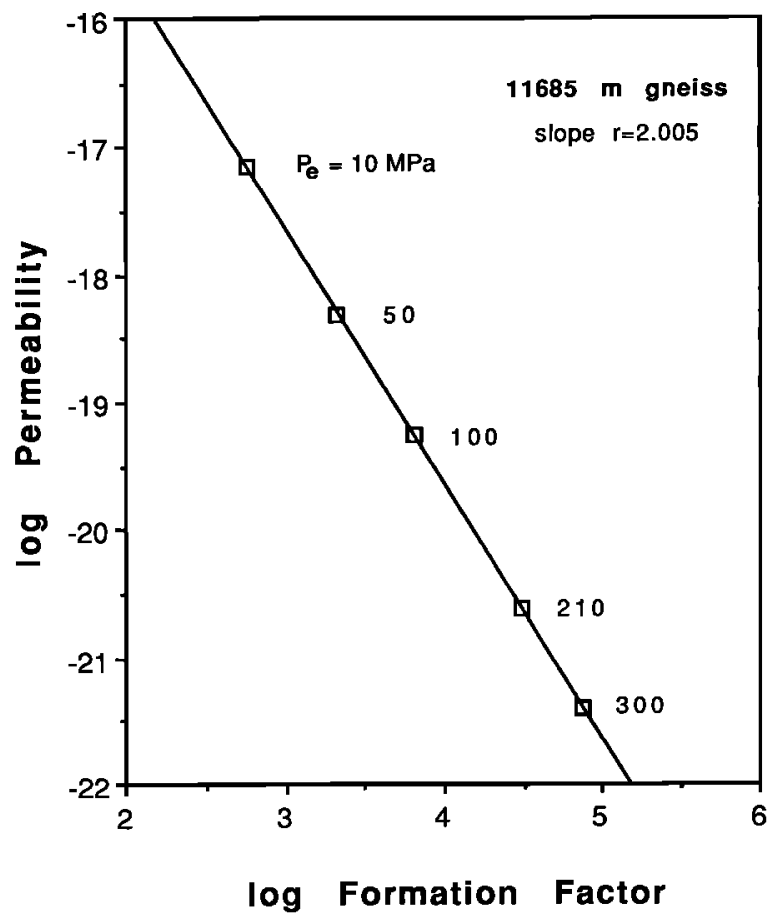

Figure 7. Log $k$ versus $\log$ formation factor. The slope $r$ is a characteristic for each rock and is a measure of the sensitivity of the tortuosity to changes in crack aperture.

$$
d\left(k^{n}\right) / d(\ln P)=\sqrt{2 / 3} h\left(c^{-1 / 2 r}\right) .
$$

This latter expression (the factor $c^{-1 / 2 r}$ was incorrectly omitted in equation (3) of Lockner et al. [1991]) is an alternative method of applying the permeability/resistivity data to determine $h$, when intercept $c$ and slope $r$ are known for a particular rock. Note that if only permeability/pressure data are available, then one can construct a plot using typical $r$ values for similar rocks to observe the characteristics of crack aperture versus pressure in a qualitative way.

Other useful expressions can be derived from the equivalent channel model that incorporate volume and porosity, because the model assumes that all porosity change results from changes in the cross sectional area of the idealized channels. For instance, crack aperture is related to porosity change by

$$
\Delta(3 k F)^{1 / 2}=\left(\Delta v_{c} / V\right)\left(V / A_{s}\right)
$$

where $\left(\Delta v_{c} / V\right)$ is the change in crack porosity, $V$ is pore volume and $A_{s}$ is the surface area of the pores. With (7), the change in crack aperture of the samples can be determined by measuring the volume of fluid expelled from the rock as pressure is increased.

\section{Applying the Equivalent Channel Model to the Data}

To quantify the effects of pressure on the properties of the core samples, we apply the model presented above to the permeability and resistivity data. The crack aperture-pressure relation (equation (4)) is shown in Figure 8a for the gneissic Kola cores, together with data for Westerly granite taken from Walsh and Brace [1984]. Note that for Westerly granite the line is straight, indicating that the. asperity height distribution is independent of pressure (i.e., that the surface roughness properties of the cracks controlling flow do not vary with pressure). However, the Kola samples show a break in the slope between 100 and $200 \mathrm{MPa}$, indicating that the asperity height distribution of the cracks controlling flow changes as the pressure is increased. We interpret this to be caused by the closure of stress relief fractures, assumed to have different physical characteristics than the natural fractures in the rocks.

At effective pressures below those found in situ, the slope of the line should be dominated by the flow through stress relief fractures. Above the in situ pressure, the slope of the line should reflect the characteristics of the natural fracture population (if any). Because of the low permeabilities of these samples, and hence limited data sets, it is more difficult to estimate the slope at pressures above in situ values, as the transition is gradual. Note however, that if the two parts of the curve are approximated by straight lines, then their point of crossing (the crossover pressure) should represent the highest closure pressure of the stress relief cracks. This pressure should provide a rough estimate of the in situ effective pressure at that depth. Such a 


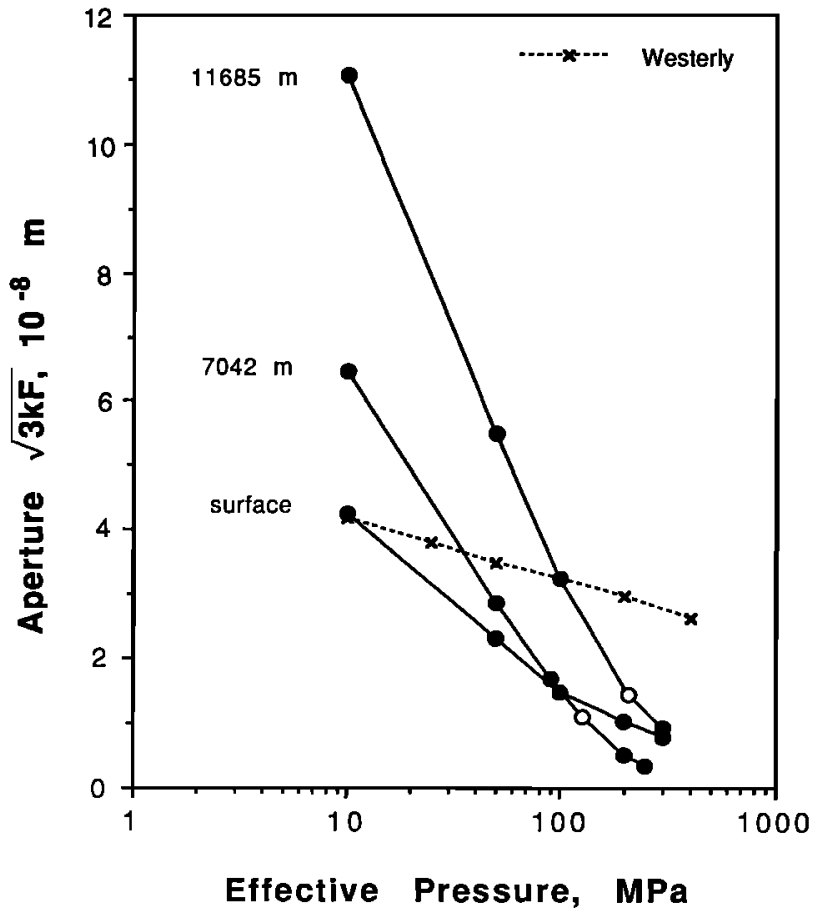

Figure 8a. Aperture versus effective pressure for gneissic Kola samples, with data for Westerly Granite [ Walsh and Brace, 1984]. Estimated in situ effective pressure values for the deep samples are shown as open symbols.

method of identifying in situ pressures may place useful bounds on the pore pressure, particularly in drill holes, where the pore pressure is poorly constrained, such as at the Kola well. Notice that for the 7042-m sample, the break in slope occurs around the expected in situ pressure of $127 \mathrm{MPa}$ (open symbol), indicating that fluid pressure in this part of the hole is near hydrostatic if one assumes a lithostatic $S_{v}$. However, the break in slope of the 11,685-m sample occurs at a pressure below the expected in situ pressure of $210 \mathrm{MPa}$ (open symbol). This may indicate that the fluid pressure is above hydrostatic by as much as $100 \mathrm{MPa}$ or that there is a locally stress-relieved zone at this depth exhibiting a sublithostatic vertical stress [e.g., Kozlovsky, 1987]. Obviously, more measurements at pressures greater than in situ are needed to make such an assessment, and we refer the reader to Lockner et al. [1991], where two other cores from near this depth in the Kola drill hole were analyzed with this method. The slight break in slope of the surface sample is unexplained at present but is probably related to the poor petrographic match and significantly larger grain size of the sample relative to the two deeper gneissic samples, or alternatively, to the possibility that the asperity distribution may be altered in near-surface rocks by weathering.

Figure $8 \mathrm{~b}$ shows the corresponding plot for the basalt and amphibolite samples from the shallower sections of the Kola drill hole. Here the plots look quite different from those in Figure 8a, due largely to the fact that the permeabilities were considerably lower than most of the gneissic samples at equivalent pressures. Note that in several cases we were unable to make permeability measurements at pressures much above the in situ effective pressure indicated on the plot. Consequently, it was not possible to identify a change in slope of the aperture/pressure relation, representing a change in rms asperity height $h$. For the $6320-\mathrm{m}$ sample, we see a gradual bend in the trend of the data around $100 \mathrm{MPa}$, much the same as with the gneissic samples. However, there are insufficient data to draw conclusions about stress relief versus natural cracks in this case because permeability was immeasurably small at effective pressures greater than $130 \mathrm{MPa}$. These mafic samples showed no obvious evidence of stress relief fracturing or disking and had low-permeability values, suggesting that the samples reached the surface relatively intact, unlike the crack-prone gneissic samples. This hypothesis is supported by seismic velocity measurements made on the same core samples (L. Vernik, personal communication, 1993), where little variation in velocity and attenuation was observed with increasing pressure. The difference in behavior between rock types correlates with quartz content since quartz has a relatively high compressibility and thermal expansion compared to other minerals [Nur and Simmons, 1970], leading to relatively greater microcrack development in the gneissic samples upon unloading.

The corresponding crack aperture plot for the KTB samples (omitted) looks much the same qualitatively as in Figure $8 b$, but because electrical resistivity was not measured for the KTB samples, only $k^{n}$ versus $\log P_{e}$

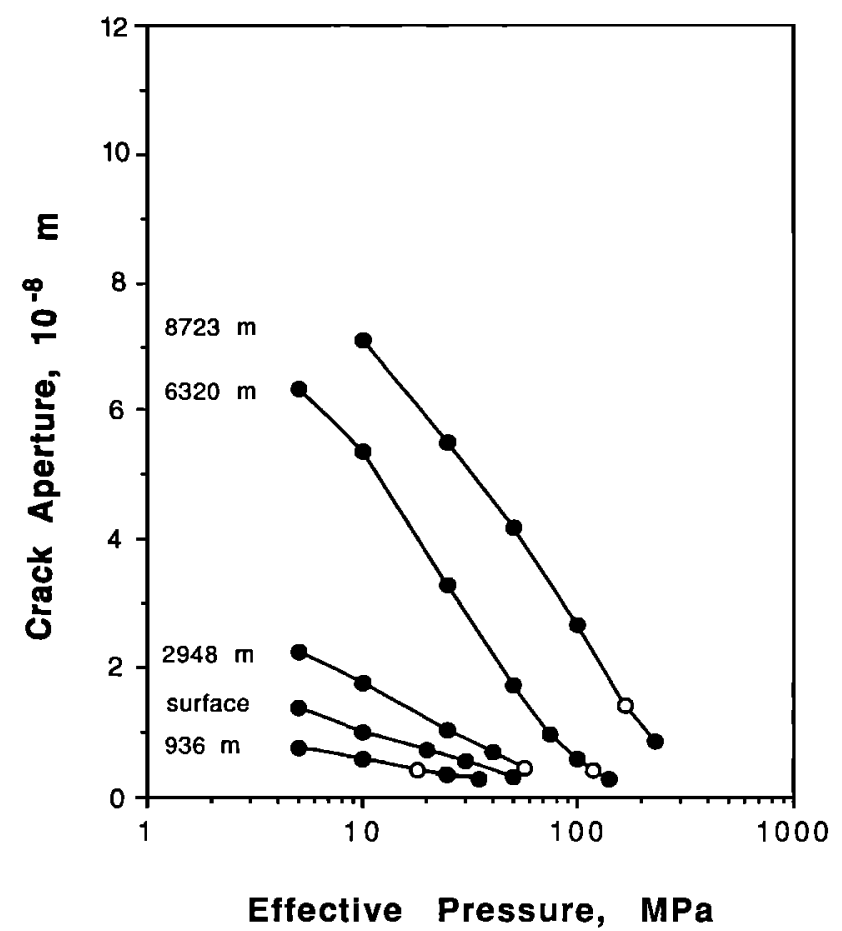

Figure 8b. Aperture versus effective pressure for mafic Kola samples, with estimated in situ effective pressure values for the deep samples shown as open symbols. Permeabilities were low enough that pressures much above in situ could not be tested. 
could be plotted (see discussion of equation (6)). Here as with the mafic Kola samples, the KTB samples had a sufficiently low permeability that the estimated in situ effective pressures could not be reached in some cases, and therefore the equivalent channel model could not be used to make estimates of in situ pressure conditions. Because crack aperture was not quantitatively determined for these samples, we will concentrate below on the Kola cores in our discussion of mafic rocks with regard to the equivalent channel model, with the assumption that the KTB samples would behave similarly.

The effect of sample depth on stress relief crack roughness for the Kola gneisses is shown in Figure 9a, where we have plotted rms asperity height $h$ taken from the slopes in Figure 8. Note that similar to the discussion of pressure sensitivity in Figure 3, this is a plot of the pressure sensitivity of permeability. However, in this case, pressure sensitivity is related to fracture roughness through a physical model (equation (4)), rather than an empirical relation combining many different factors. In Figure 9a, rms height $h$ scales in a systematic way with both depth and pressure for the gneissic samples, indicating closure of cracks with pressure and the presence of more stress relief damage for the samples recovered from greater depth. Performing the same analysis for the Kola basalts and amphibolites (Figure 9b), we see that asperity height also scales with depth. However, at the shallower depths (surface, 936 and $2948 \mathrm{~m}$ ), the values are generally low and somewhat independent of pressure, indicating that little if any stress relief cracking occurred when these samples were brought to the surface. This is not true of the

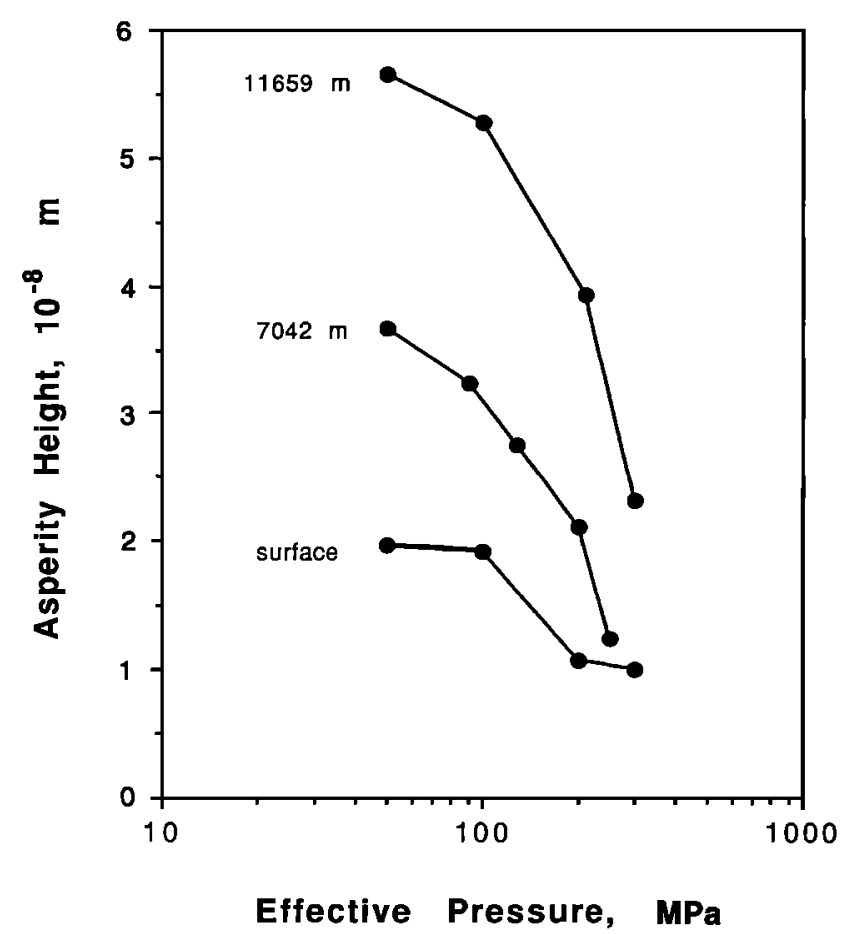

Figure 9a. Rms asperity height versus pressure for gneissic Kola samples showing systematic trends with pressure and depth.

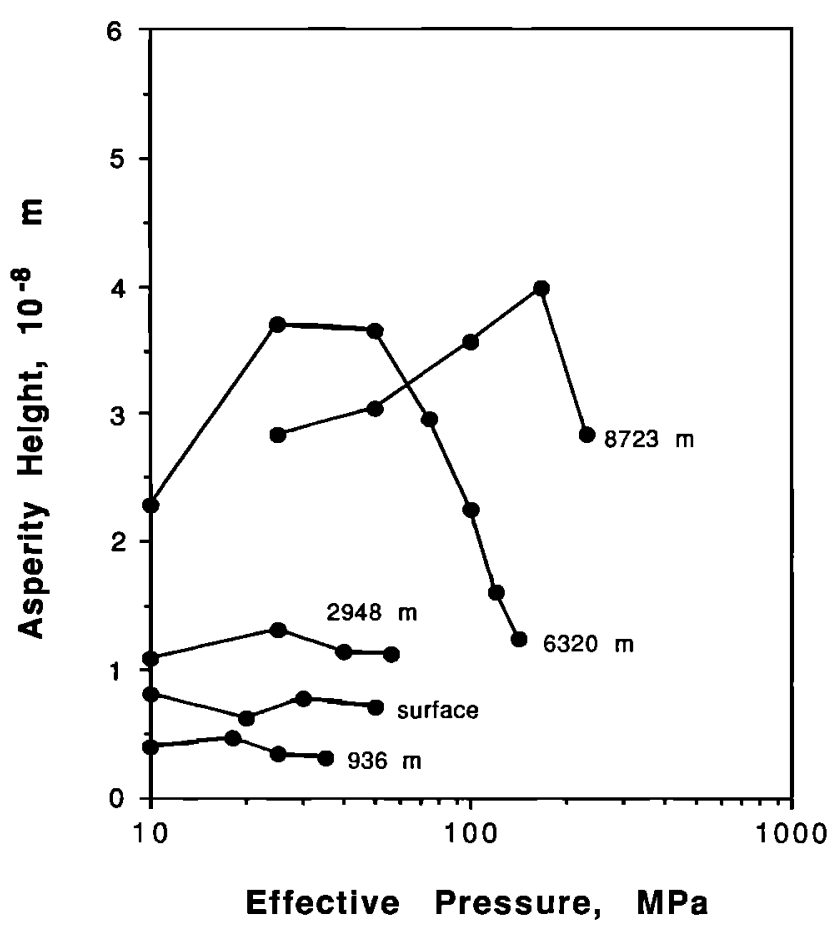

Figure 9b. Rms asperity height versus pressure for mafic Kola samples. The general lack of stress relief fractures in the shallower samples is evident by the low and fairly constant asperity height values.

two deeper samples, which showed variations in asperity height with applied pressure. These data are difficult to interpret because of their initial upward trends (particularly $8723 \mathrm{~m}$ ); however, the overall crack roughness is consistent with the range observed for the $7-\mathrm{km}$ gneissic sample. Although the physical cause for the initial increase in asperity height is unknown, these asperity height values approach those of the shallower mafic samples, which may represent the typical average asperity height of the in situ cracks/grain boundaries. From this analysis we draw the important conclusion that there exists a cutoff depth (between our 3 - and 6-km samples) above which the mafic rocks show little decompression damage. This interpretation is consistent with largerscale observations of crack damage in the retrieved core [Kozlovsky, 1987].

The crack aperture/porosity change relation (equation (7)) is shown for all the Kola samples in Figure 10. Here the basalt samples are distinct from the gneisses and amphibolites because of their low porosity and the fact that they have fewer (or no) stress relief fractures/thermal cracks. None of the samples displayed the linear relation predicted from equation (7), indicating again that the characteristics of the crack populations changed with pressure due to the closure of stress relief fractures. This trend supports our initial assumption that the geometric properties of the two crack populations are inherently different. However, from the gradual change in slope of the curves in Figure 10 (particularly, the mafic samples), we conclude that finding the crossover pressure to determine in situ stresses from this volume data set can lead to 


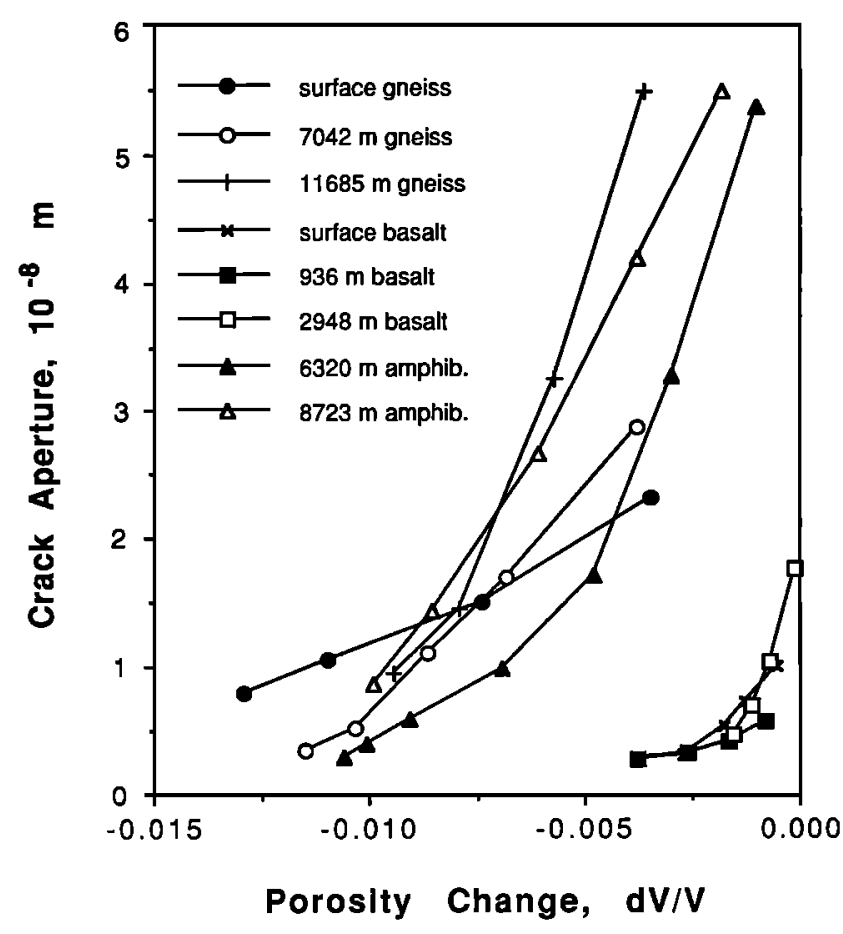

Figure 10. Asperity versus porosity change for the Kola samples. These plots do not follow the straight line predicted by equation (10), suggesting that the character of the crack population changes with increasing pressure due to the closure of stress relief cracks.

ambiguous results for several of the samples. This may be due to irregularities in the pressure/volume-change measurements due to time-dependent crack-closure effects, or errors in measuring the extremely low $(<1 \%)$ porosity. Whatever the reason, Lockner et al. [1991] had success with this method on Kola samples from $11 \mathrm{~km}$, where the crossover pressure from the aperture/porosity relation matched that of the aperture/pressure relation, suggesting either elevated in situ pore pressures of up to $100 \mathrm{MPa}$ above hydrostatic or low vertical stresses relative to lithostatic.

These tests on samples of differing mineralogy and depth have shown that using the equivalent channel model to predict in situ pressures is more appropriate for the higher-permeability quartz-rich core samples than the extremely low permeability mafic rocks encountered in the midsections of the hole. Microcracking due to differential expansion of minerals is important in granites because of the relatively high compressibility and thermal expansion of quartz. However, in our mafic samples, which were relatively less fractured (and essentially unfractured above $3 \mathrm{~km}$ ), test pressures could not exceed the estimated in situ values due to the lower measurement limit of the experimental apparatus. We were thus unable to correlate specific stress relief crack closure pressures with depth, although stress relief damage did correlate with depth in a general way. The equivalent channel model does, however, provide useful information on average crack aperture, asperity height, electrical properties and other parameters and, most importantly, how these parameters change with pressure. We anticipate that this indirect approach may prove useful for providing bounds on in situ pressures in other drill holes where pore pressures and/or tectonic stresses are not well constrained, providing that the permeabilities of the core samples fall within a suitable test range.

\section{Conclusions}

1. Matrix permeabilities of the Kola core samples from depths of up to $12 \mathrm{~km}$ covered 6 orders of magnitude, from $10^{-17}$ to $10^{-23} \mathrm{~m}^{2}$ at effective pressures from 5 to $300 \mathrm{MPa}$. This broad range reflects the fact that stress relief microfractures enhance the permeability and pressure sensitivity of the core samples at low effective pressures, where these cracks are not yet closed. When measured at the estimated in situ pressures, the permeabilities ranged between $5 \times 10^{-21}$ and $5 \times 10^{-23} \mathrm{~m}^{2}$, significantly lower than those reported at lower confining pressures [Bayuk et al., 1987], illustrating the importance of measuring permeability at the appropriate pressures. Permeabilities of the quartz-rich specimens were generally higher than the mafic samples due to their larger grain size and more abundant microfractures, many of which were apparently introduced during drilling and core retrieval.

2. Permeabilities of the KTB basalts were very low $\left(10^{-19}\right.$ to $10^{-23} \mathrm{~m}^{2}$ at pressures from 5 to $\left.60 \mathrm{MPa}\right)$ and sensitive to pressure, similar to the Kola mafic samples. Unlike most rocks, permeability for many of the KTB samples followed the simple relation $-\log k \propto P_{e}$, although this may be a result of the limited pressure range over which permeability could be measured.

3 . Stress relief and natural microfractures have physical differences that can be distinguished using the equivalent channel model of Walsh and Brace [1984] to estimate crack closure pressures. Applying the model to the quartz-rich Kola samples suggests that in situ pressures may be above hydrostatic near the bottom of the drill hole or that the vertical stress may be locally sublithostatic. The analysis was not appropriate for the mafic samples because they are relatively crack-free in situ, and remain so even after core retrieval, particularly for samples from depths above $3 \mathrm{~km}$.

Acknowledgments. We wish to thank J. Lauterjung for providing us with the samples from the KTB drill hole.

\section{References}

Bayuk, E. I., B. P. Belikov, L. I. Vernik, M. P. Volarovitch, Yu. I. Kuznetsov, G. E. Kuzmenkova, and N. N. Pavlova, Rock density, porosity and permeability, in The Superdeep Well of the Kola Peninsula, edited by Ye. A. Kozlovsky, pp. 332-338, Springer-Verlag, New York, 1987.

Bear, J., Dynamics of Fluids in Porous Media, Elsevier, New York, 166 pp., 1972.

Borevsky, L. V., G. S. Vartanyan, and T. B. Kulikov, Hydrogeological essay, in The Superdeep Well of the Kola 
Peninsula, edit by Ye. A. Koslovsky, pp. 271-287, Springer-Verlag, New York, 1987.

Brace, W. F., Permeability of crystalline and argillaceous rocks, Int. J. Rock Mech. Min. Sci., 17, 241-251, 1980.

Brace, W. F., J. B. Walsh, and W. T. Frangos, Permeability of granite under high pressure, J. Geophy. Res., 73(6), 2225-2236, 1968.

Brantley, S.L., B. Evans, S. H. Hickman, and D. A. Crerar, Healing of microcracks in quartz: Implications for fluid flow, Geology, 18, 136-139, 1990.

Carlson, S. R., and H. F. Wang, Microcrack porosity and in situ stress in Illinois borehole UPH 3, J. Geophy. Res., 91(B10), 10,421-10,428, 1986.

David, C., Geometry of flow paths for fluid transport in rocks, J. Geophys. Res., 98(B7), 12,267-12,278, 1983.

Dyke, C. G., Core discing: Its potential as an indicator of principal in situ stress directions, in Rock at Great Depth, edited by V. Maury, and D. Fourmaintraux, pp. 10571064, A.A. Balkema, Rotterdam, The Netherlands, 1989.

Emmermann, R., H.-G. Dietrich, J. Lauterjung, and T. Wohrl, (Eds.), Results of Geoscrentific Investigation in the KTB Field Laboratory, Niedersachsisches Landesamt fur Bodenforschung, Hannover, 1992.

Engelder, T., Stress Regimes in the Lithosphere, 457 pp., Princeton Univ. Press, Princeton, N.J., 1993.

Greenwood, J. A., and J.B. Williamson, Contact of nominally flat surfaces, Proc. R. Soc. London, Ser. A, 295, 300-319, 1966.

Kazansky, V. I., Y. P. Smirnov, and Yu. I. Kuznetsov, Shear zones and mineralized fissures, in The Superdeep Well of the Kola Peninsula, edited by Ye.A. Kozlovsky, pp. 223242, Springer-Verlag, New York, 1987.

Kowallis, B. J. and H. F. Wang, Microcrack study of granitic cores from Illinois deep borehole UPH 3, J. Geophy. Res., 88(B9), 7373-7380, 1983.

Kozlovsky, Ye. A. (Ed.), The Superdeep Well of the Kola Penınsula, 559 pp., Springer-Verlag, New York, 1987.

Kremenetsky, A. A., The geologic nature of seismic boundaries in the continental crust, Super-deep Continental Drilling and Deep Geophysical Sounding, edited by K. Fuchs, Ye. A. Kozlovsky, A. I. Krivtsov, and M. D. Zoback, pp. 393-407, Springer-Verlag, New York, 1990.

Kremenetsky, A. A., Models and Cross Sectrons of the Earth's Crust Based on Super-Deep Drilling Data of the USSR, 164 pp., Inst. of the Mineralogy, Geochemistry, and Crystal Chemistry of Rate Elements, Moscow, 1991.

Kulander, B. R., S. L. Dean, and B. J. Ward, Fractured core analysis: Interpretation, logging and use of natural and induced fractures in core, in $A A P G$ Methods in Exploration Series, vol. 8, American Association of Petroleum
Geologists, Tulsa, Okla., 1990.

Lockner, D., S. Hickman, V. Kuksenko, A. Ponomarev, A. Sidorin, J. Byerlee, and B. Khakaev, Laboratorydetermined permeability of cores from the Kola superdeep well, USSR, Geophy. Res. Lett., 18(5), 881-884, 1991.

Moore, D. E., L. Liu, R. Summers, D. Lockner, and J. D. Byerlee, Permeability of granite at elevated temperatures, Eos, Trans. $A G U, 74(43), 568,1993$.

Morrow, C. A., and J.D. Byerlee, Permeability of core samples from Cajon Pass scientific drillhole: Results from 2100 to $3500 \mathrm{~m}$ depth, J. Geophy. Res., 97(B3), 51455151, 1992.

Morrow, C.A., Z. Bo-Chong, and J. D. Byerlee, Effective pressure law for permeability of Westerly Granite under cyclic loading, J. Geophy. Res., 91(B3), 3870-3876, 1986.

Nur A., and Simmons, G., The origin of small cracks in igneous rocks, Int. J. Rock Mech. Min. Sci. Geomech. Abstr., 7, 307-314, 1970.

Pavlenkova, N. I., The nature of seismic boundaries in the continental lithosphere, Tectonophysics, 154, 211-225, 1988.

Sibson, R. H., Fluid flow accompanying faulting: Field evidence and models, in Earthquake Prediction: An International Review, edited by D. W. Simpson and P. G. Richards, Maurice Euing Ser. vol 4, pp. 593-603, AGU, Washington D.C., 1981.

Smith, D. L., and B. Evans, Diffusional crack healing in quartz, J. Geophys. Res., 89(B6), 4125-4135, 1984.

Walsh, J. B., and W. F. Brace, The effect of pressure on porosity and the transport properties of rock, J. Geophy. Res., 89(B11), 9425-9431, 1984.

Wang, H. F. and G. Simmons, Microcracks in crystalline rock from 5.3-km depth in the Michigan Basin, J. Geophys. Res., 83(B12), 5849-5856, 1978.

Wang, C.-Y., and Y. Sun, Oriented microfractures in the Cajon Pass drill cores: Stress field near the San Andreas Fault, J. Geophy. Res., 95(B7), 11,135-11,142, 1990.

S. Hickman, D. Lockner, and C. Morrow, U.S. Geological Survey, Menlo Park, CA 94025.

T. Röckel, Kontinentales Tiefbohrprogramm der Bundesrepublik, KTB Oberfalz, D-8486 Windischeschenbach, Germany.

M. Rusanov, Nedra Enterprise, 184415 Zapolyarny, Murmansk Region, Russia.

(Received July 21, 1993; revised December 2, 1993; accepted December 6, 1993.) 